\title{
Adipokines and Arterial Stiffness in the Elderly
}

This article was published in the following Dove Press journal:

Vascular Health and Risk Management

\author{
Francesco Fantin' \\ Eleonora Disegna' \\ Gisella Manzato' \\ Gabriele Comellato' \\ Elena Zoico' \\ Andrea P Rossi $\left(\mathbb{D}^{1}\right.$ \\ Gloria Mazzali' \\ Chakravarthi Rajkumar $\mathbb{I D}^{2}$ \\ Mauro Zamboni ${ }^{3}$ \\ 'Department of Medicine, Section of \\ Geriatrics Medicine, University of \\ Verona, Verona, Italy; ${ }^{2}$ Department of \\ Medicine, Brighton and Sussex Medical \\ School, Brighton, UK; ${ }^{3}$ Department of \\ Surgery, Dentistry, Paediatrics and \\ Gynaecology, Section of Geriatrics, \\ University of Verona, Verona, Italy
}

Correspondence: Francesco Fantin Department of Medicine, Section of Geriatric Medicine, University of Verona, Piazzale Stefani I, Verona 37I 26 Italy Tel $+39045-8122537$

Fax +39 045-8122043

Email francesco.fantin@univr.it
Introduction: The aim of this study was to evaluate the relationship between adipokines and arterial stiffness in a group of 85 elderly subjects and the role of leptin and adiponectin on subclinical vascular damage, defined by a PWV $>10 \mathrm{~m} / \mathrm{s}$.

Methods: In each subject, we evaluated anthropometry, body composition by DXA (fat mass, fat mass $\%$, lean mass), metabolic variables, leptin, adiponectin, systolic, diastolic, mean arterial pressure and pulse pressure (SBP, DBP, MAP, PP), carotid-femoral pulse wave velocity (cfPWV) and carotid-radial pulse wave velocity (crPWV).

Results: In the study population, significant associations were observed between cfPWV and crPWV, age, SBP, MAP, waist circumference, fat body mass and leptin. The study population was subdivided in 2 subgroups according to adipokine patterns: group 1 included patients with high adiponectin and low leptin, and group 2 patients had high leptin and low adiponectin. SBP, PP, cfPWV were significantly higher in subjects with high leptin and low adiponectin (group 2). Even after adjustment for gender, fat mass\%, MAP, HDL cholesterol and triglycerides, cfPWV was higher in group 2 than group 1. In a logistic binary regression on the entire population, considering subclinical vascular damage as a dependent variable and age, gender, MAP, fat mass $\%$, triglycerides, HDL cholesterol and category of subjects with high leptin and low adiponectin as independent variables, MAP and category of subjects with high leptin and low adiponectin were significant predictors (OR, respectively, 1.09 and 3.61).

Conclusion: In conclusion, in the elderly, the presence at the same time of high leptin levels and low adiponectin levels seems to have synergic effects on arterial stiffness.

Keywords: leptin, adiponectin, elderly, arterial stiffness

\section{Introduction}

It has been shown that traditional cardiovascular risk factors such as hypertension, obesity, diabetes, dyslipidemia and metabolic syndrome modify the structural and functional characteristics of arteries reducing their compliance and increasing arterial stiffness. $^{1-4}$

Several studies showed a significant association between visceral adipose tissue (VAT) and increased carotid-femoral pulse wave velocity (cfPWV). ${ }^{3-5}$ It has been proposed that adipokines (as IL-6, plasminogen activating factor inhibitor and leptin) may be a link between VAT and endothelial dysfunction. ${ }_{-}^{6-8}$

Among adipokines, adiponectin and leptin have been widely studied because of their close relation to fat distribution and cardiovascular risk; their levels also change with age even if study results are controversial. ${ }^{9,10}$ Certainly, leptinresistance, a condition closely related to hyperleptinemia, is higher in elderly and age-related fat distribution plays a key role in adipokine panel changes. ${ }^{11,12}$ Visceral obesity is associated with hyperleptinemia, leptin-resistance and hypoadiponectinemia configuring a high cardiovascular risk phenotype. ${ }^{13}$ 
Adiponectin and leptin seem to play a key role in the regulation of vascular function and in the pathogenesis of arterial stiffening and hypertension. ${ }^{14}$

Moreover, leptin has been proposed as a link between obesity and hypertension. ${ }^{15}$ However, several conditions related to obesity such as low-grade inflammation ${ }^{16}$ and insulin resistance ${ }^{17}$ may influence this association. High leptin plasma levels indeed seem to have opposite effects activating sympathetic receptors of the central nervous system (CNS) and determining vascular smooth muscle cell hyperplasia, ${ }^{18}$ endothelial oxidative stress ${ }^{19}$ and activation of renin-angiotensin-aldosterone system (RAAS). ${ }^{20}$

A large cross-sectional study of 6148 healthy subjects showed an association between leptin and PWV. In resistant hypertensive patients plasma leptin concentration was associated with arterial stiffness, and leptin levels were higher in patients with uncontrolled hypertension. ${ }^{21}$

On the other hand, adiponectin seems to have vasculoprotective effects by inducing endothelial e-NOS expression and activation, ${ }^{22}$ suppressing vascular smooth muscle cell proliferation and migration ${ }^{23}$ and repairing injured vessels with its interaction with selected molecules in subendothelial space and medial wall exposed to the lumen. ${ }^{24}$

Several cross-sectional studies showed an association between hypoadiponectinemia and arterial stiffness. ${ }^{25-27}$ A meta-analysis including 17,598 patients found a lower level of adiponectin in hypertensive subjects compared with non-hypertensives. ${ }^{25}$ Indeed, two longitudinal studies found that baseline adiponectin values were independent predictors of aortic stiffness progression measured with hfPWV and baPWV. ${ }^{26,27}$

Finally, Scuteri et al showed that a specific adipokine pattern characterized by high levels of leptin in addition to low levels of adiponectin could have synergic effect in increasing arterial stiffness regardless of traditional cardiovascular risk factor. ${ }^{13}$

The aim of our study was to evaluate the relationships between leptin, adiponectin, body composition and arterial stiffness in a group of 85 elderly subjects.

\section{Methods}

\section{Subjects}

Eighty-five Caucasian subjects (50 women, 35 men) with mean age $69.54 \pm 4.15$ years and mean BMI $26.29 \pm$ $3.84 \mathrm{~kg} / \mathrm{m}^{2}$ took part in the study. The subjects were recruited by advertisements in local GPs of Verona, Italy. Subjects were eligible if free of known CV diseases and did not assume any medications affecting arterial compliance, such as antihypertensive, statin treatment, and hormone replacement therapy. Only post-menopausal women were recruited.

All subjects had stable weight during the past 6 months. None of the subjects was affected by diabetes, cancer, or liver, kidney and thyroid diseases, and had no evidence of cardiovascular disease (CVD) except hypertension, which was diagnosed after our visit but not known at recruitment. Patients with renal impairment (SerumCreatinine $>1.35 \mathrm{mg} / \mathrm{dl}$ ) were excluded. All subjects were non-smokers. The study was approved by the Ethical Committee of the University of Verona. The study was conducted in accordance with the Declaration of Helsinki. All participants gave written informed consent to be involved in the research study.

All subjects underwent a careful clinical assessment before the study.

\section{Anthropometric Variables}

With the subject barefoot and wearing light indoor clothing, body weight was measured to the nearest $0.1 \mathrm{~kg}$ (Salus scale, Milan, Italy), and height to the nearest $0.5 \mathrm{~cm}$ using a stadiometer (Salus stadiometer, Milan, Italy). BMI was calculated as body weight adjusted by stature $\left(\mathrm{kg} / \mathrm{m}^{2}\right)$. Waist circumference was obtained with a measuring tape at the level of the narrowest part of the torso as viewed anteriorly.

\section{Dual Energy X-Ray Absorptiometry (DXA)}

Total body fat, trunk and appendicular, legs and total fatfree mass (FFM) were determined using a DXA Hologic QDR 4500 fan beam densitometer with software version 8.21. The characteristics and physical concepts of DXA measurements have been described elsewhere. ${ }^{28}$

\section{Blood Pressure and Arterial Stiffness Measurements}

Brachial blood pressure (BP) was measured three times in a time frame of 15 minutes using a mercury sphygmomanometer in the left arm of the subject, following the standard methodology suggested by the guidelines. The mean of three readings was considered as the subject's BP. The $\mathrm{BP}$ was recorded immediately prior to tonometric recording. Subject conditions were standardized according to established guidelines: all subjects were fasting, and all 
subjects had refrained from consumption of alcohol or caffeine for the preceding $24 \mathrm{~h}$. MAP was calculated by adding $1 / 3$ of the pulse pressure (systolic minus diastolic) to the diastolic pressure.

Arterial stiffness was measured non-invasively using a small portable device called PulsePen (Diatecne, Milan, Italy), ${ }^{29}$ as previously explained. ${ }^{3}$ Its software provides central aortic pressure values, an assessment of arterial pulse wave contours, an estimation of reflection waves and measurements of PWV. PulsePen determines the PWV by a single probe placed at two sites in rapid succession, using the ECG trace as reference. The operator starts by positioning the probe at the common carotid artery, the central detection site, while simultaneously performing ECG. Then, the same procedure is followed for the femoral artery, in cfPWV, and for the radial artery in the crPWV. When the difference between heart rate recorded during the carotid measurement and that recorded during the femoral or radial measurement was equal to or greater than $10 \%$, the PWV measurement was repeated. The difference in heart rate is indicated by the PulsePen software.

The PWV was calculated as distance between the measurement sites divided by transit time delay between femoral and carotid pulse wave and expressed in meters per second.

The distance of the pulse wave transit was the difference between the distance from suprasternal notch to femoral point of application of the tonometer and the distance from carotid point of tonometer application and the suprasternal notch. The time delay was measured between the feet of the peripheral artery (femoral or radial) and carotid waveforms. The foot of the wave is defined at the end of diastole, when the steep rise of the waveform begins. The duration of the examination was generally of 10-15 min for each patient.

Coefficient of variation for cfPWV measured by PulsePen device in our laboratory was $6.7 \%$. It was obtained by double evaluation in 25 participants.

\section{Biochemical Analyses}

Venous blood samples for all metabolic assessments were obtained after the subjects fasted overnight. Plasma glucose was measured with a glucose analyzer (Beckman Instruments Inc., Palo Alto, CA). The intra-assay CV was $1.5 \%$. Cholesterol and triglycerides concentrations were determined with an automated enzymatic method (Auto analyzer; Technicon, Tarrytown, NY). Highdensity-lipoprotein (HDL) cholesterol was measured by using the method of Warnick and Albers. LDL cholesterol was calculated using the Friedwald formula. HbA1c was measured by high-performance liquid chromatography (Bio-Rad Diagnostics Group, Hercules, CA).

Serum leptin and adiponectin were measured using specific enzyme-linked immunoassay kits (from DBCDiagnostic Biochem Canada and B-Bridge, respectively). The sensitivity of the assays was $0.5 \mathrm{ng} / \mathrm{mL}$ for leptin and $0.02 \mathrm{ng} / \mathrm{mL}$ for adiponectin. High-sensitivity C-reactive protein (hs-CRP) was measured with the immunoturbidimetric method. The detection threshold was $0.5 \mathrm{mg} / \mathrm{L}$, the reference interval was $3 \mathrm{mg} / \mathrm{L}$, and analytic variability was $5 \%$.

\section{Statistical Analyses}

Results are shown as mean \pm SD. Variables not normally distributed were log-transformed before analysis. Pearson's correlations were used to test the relationship between the variables. A subanalysis was done with 2 groups according to adipokine patterns. Group 1 included subjects with high adiponectin levels ( $3^{\text {rd }}$ tertile) and low leptin levels ( $1^{\text {st }}$ and $2^{\text {nd }}$ tertiles); group 2 included subjects with high leptin levels ( $3^{\text {rd }}$ tertile) and low adiponectin levels ( $1^{\text {st }}$ and $2^{\text {nd }}$ tertiles). The analysis of variance (ANOVA) was used to compare mean values of cfPWV of the groups. A post hoc analysis was used to evaluate the differences between the 2 groups.

A backward regression model was used to evaluate the joint effect of independent variables on cfPWV. Age, gender, MAP, fat mass \%, HDL cholesterol, triglycerides and adipokine categories were considered as independent variables, with cfPWV as the dependent variable. The same model was used to perform a binary logistic regression model to evaluate the joint effect of independent variables on subclinical cardiovascular damage, defined as cfPWV $>10 \mathrm{~m} / \mathrm{s}$ values, as previously published. ${ }^{30}$

A $p$ value of less than 0.05 was considered significant. All analyses were performed using SPSS statistical program (version 20.0 for Windows).

\section{Results}

Main characteristics of the study population are shown in Table 1.

Eighty-five elderly patients were evaluated, $58.8 \%$ of them were women $(n=50)$ and $41.2 \%$ men $(n=35)$. The mean age was $69.54 \pm 4.15$ years (range 65-81) and the mean BMI was $26.29 \pm 3.84 \mathrm{~kg} / \mathrm{m}^{2}$ (range 18.83-36.44). As high as 64.7\% had high cholesterol levels $(n=55)$, 
Table I Characteristics of the Study Population

\begin{tabular}{|c|c|c|c|c|}
\hline & $\begin{array}{l}\text { Mean } \pm \text { Standard Deviation } \\
\text { (85) }\end{array}$ & $\begin{array}{l}\text { Women } \\
\text { (50) }\end{array}$ & $\begin{array}{l}\text { Men } \\
(35)\end{array}$ & $\mathbf{P}$ \\
\hline Age (years) & $69.54 \pm 4.15$ & $69.23 \pm 3.80$ & $70.03 \pm 4.66$ & 0.37 \\
\hline Body weight (kg) & $70.38 \pm 13.90$ & $64.85 \pm 11.40$ & $78.90 \pm 13.19$ & $<0.001$ \\
\hline BMI $\left(\mathrm{kg} / \mathrm{m}^{2}\right)$ & $26.29 \pm 3.84$ & $25.82 \pm 3.7 \mid$ & $27.02 \pm 3.97$ & 0.14 \\
\hline Waist circumference $(\mathrm{cm})$ & $88.58 \pm 11.75$ & $83.62 \pm 9.85$ & $96.42 \pm 10.23$ & $<0.001$ \\
\hline Hip circumference $(\mathrm{cm})$ & $99.76 \pm 7.83$ & $99.64 \pm 8.32$ & $99.95 \pm 7.12$ & 0.85 \\
\hline Fat body mass $(\mathrm{kg})$ & $22.44 \pm 71.79$ & $23.40 \pm 67.42$ & $20.99 \pm 76.60$ & 0.11 \\
\hline Fat body mass (\%) & $32.15 \pm 7.24$ & $36.06 \pm 5.07$ & $26.24 \pm 5.91$ & $<0.001$ \\
\hline Lean body mass (kg) & $44.80 \pm 94.87$ & $38.5 I \pm 50.35$ & $54.33 \pm 60.27$ & $<0.001$ \\
\hline Glycemia (mg/dL) & $91.97 \pm 13.76$ & $92.33 \pm 12.07$ & $91.38 \pm 16.27$ & 0.75 \\
\hline Total cholesterol (mg/dL) & $215.98 \pm 36.82$ & $222.98 \pm 34.52$ & $204.85 \pm 38.11$ & 0.02 \\
\hline HDL cholesterol (mg/dL) & $59.61 \pm \mid 7.21$ & $63.67 \pm 17.70$ & $53.18 \pm 14.43$ & 0.01 \\
\hline LDL cholesterol (mg/dL) & $|35.07 \pm 3| .02$ & $139.07 \pm 30.40$ & $|28.70 \pm 3| .37$ & 0.13 \\
\hline Triglycerides (mg/dL) & $104.52 \pm 46.31$ & $100.94 \pm 45.82$ & $|1| 0.21 \pm 47.20$ & 0.36 \\
\hline Glycated Hemoglobin (\%) & $5.72 \pm 0.33$ & $5.80 \pm 0.30$ & $5.59 \pm 0.34$ & 0.01 \\
\hline $\mathrm{SBP}(\mathrm{mmHg})$ & $147.50 \pm 19.78$ & $144.84 \pm 19.40$ & $151.46 \pm 19.95$ & 0.12 \\
\hline DBP $(\mathrm{mmHg})$ & $84.04 \pm 8.96$ & $83.02 \pm 9.25$ & $85.57 \pm 8.41$ & 0.18 \\
\hline PP (mm Hg) & $63.46 \pm 15.85$ & $61.82 \pm|5.7|$ & $65.89 \pm 15.95$ & 0.23 \\
\hline $\mathrm{MBP}(\mathrm{mmHg})$ & $105.20 \pm 11.32$ & $103.62 \pm 11.30$ & $107.53 \pm 11.10$ & 0.11 \\
\hline cf PWV (m/s) & $10.27 \pm 2.44$ & $7.93 \pm 1.16$ & $8.67 \pm 1.26$ & 0.01 \\
\hline cr PWV (m/s) & $8.21 \pm 1.25$ & $10.15 \pm 2.32$ & $10.47 \pm 2.64$ & 0.59 \\
\hline Leptin (ng/mL) & $15.92 \pm 13.18$ & $20.65 \pm 13.99$ & $9.15 \pm 8.18$ & $<0.001$ \\
\hline Adiponectin $(\mu \mathrm{g} / \mathrm{mL})$ & $14.74 \pm 7.23$ & $17.94 \pm 7.04$ & $10.04 \pm 4.45$ & $<0.001$ \\
\hline
\end{tabular}

$15.3 \%$ was obese $(n=13)$ and $36.5 \%$ was overweight $(n=31)$.

Women had a body fat mass percent significantly higher than men $(36.06 \pm 5.07 \%$ vs $26.24 \pm 5.91 \%$; $\mathrm{p}<0.001)$. Men had lean body mass significantly higher than women $(54.33 \pm 60.27 \mathrm{~kg}$ vs $38.51 \pm 50.35 \mathrm{~kg}$; $\mathrm{p}<0.001)$. Women had leptin and adiponectin values significantly higher than men $(20.65 \pm 13.99 \mathrm{ng} / \mathrm{mL}$ vs 9.15 $\pm 8.18 \mathrm{ng} / \mathrm{mL} ; \mathrm{p}<0.001$ and $17.94 \pm 7.04 \mu \mathrm{g} / \mathrm{mL}$ vs 10.04 $\pm 4.45 \mu \mathrm{g} / \mathrm{mL} ; \mathrm{p}<0.001$, respectively). Total cholesterol and HDL cholesterol were significantly higher in women as well $(222.98 \pm 34.52 \mathrm{mg} / \mathrm{dL}$ vs $204.85 \pm 38.11 \mathrm{mg} / \mathrm{dL}$; $\mathrm{p}=0.02$ and $63.67 \pm 17.70 \mathrm{mg} / \mathrm{dL}$ vs $53.18 \pm 14.43 \mathrm{mg} / \mathrm{dL}$; $\mathrm{p}=0.01$, respectively). cfPWV resulted significantly higher in men than in women $(8.67 \pm 1.26 \mathrm{~m} / \mathrm{s}$ vs $7.39 \pm 1.16 \mathrm{~m} / \mathrm{s}$; $\mathrm{p}<0.01)$.

In the entire study population significant associations were observed between cfPWV and crPWV ( $\mathrm{r}=0.37$, $\mathrm{p}=003)$, age $(\mathrm{r}=0.27, \mathrm{p}=0.02), \operatorname{SBP}(\mathrm{r}=047, \mathrm{p}<001)$, MAP $(\mathrm{r}=036 ; \mathrm{p}=001)$, waist circumference $(\mathrm{r}=026 ; \mathrm{p}=002)$, fat body mass $(r=031 ; p=005)$ and leptin $(r=025 ; p=004)$ (data not shown in Table).Significant associations were observed in women between cfPWV and crPWV $(\mathrm{r}=032$, $\mathrm{p}<005)$, SBP ( $\mathrm{r}=047, \mathrm{p}<001)$, MAP ( $=040 ; \mathrm{p}<001)$, DBP $(\mathrm{r}=044 ; \mathrm{p}<001)$, waist circumference $(\mathrm{r}=031 ; \mathrm{p}<005)$, fat body mass $(\mathrm{r}=038 ; \mathrm{p}<001)$ and leptin $(\mathrm{r}=036 ; \mathrm{p}<005)$ (data not shown in Table), whereas we did not observe a significant correlation between cfPWV and Adiponectin $(\mathrm{r}=-016$, NS). Significant associations were observed in men between cfPWV and age $(\mathrm{r}=045 ; \mathrm{p}<005)$, crPWV $(\mathrm{r}=042 ; \mathrm{p}<005)$, SBP $(\mathrm{r}=039 ; \mathrm{p}<005)$, DBP $\quad(\mathrm{r}=042$; $\mathrm{p}<005)$ and leptin $(\mathrm{r}=039 ; \mathrm{p}<005)$ (data not shown in Table), whereas we did not observe a significant correlation between cfPWV and Adiponectin.

Table 2 shows a comparison between main anthropometric, metabolic blood pressure and arterial stiffness variables of the study population divided into two groups: group 1 with high adiponectin and low leptin, group 2 with high leptin and low adiponectin. In group 2, body weight, BMI, waist circumference, hip circumference, fat body mass, fat body mass percent, and lean body mass were significantly higher than in group 1. HDL cholesterol was significantly higher in group 1 than in group 2 and triglycerides were significantly higher in group 2 than in group 1 .

SBP and PP were significantly higher in subjects with high leptin and low adiponectin than in which with high 
Table 2 Comparison Between Main Anthropometric, Metabolic and Cardiovascular Variables of the Study Population Divided into Two Groups: Group I with High Adiponectin (3rd Tertile) and Low Leptin (Ist and 2nd Tertile); Group 2 with High Leptin (3rd Tertile) and Low Adiponectin (Ist and 2nd Tertile)

\begin{tabular}{|c|c|c|c|}
\hline & $\begin{array}{l}\text { High } \\
\text { Adiponectin } \\
\text { and } \\
\text { Low Leptin }\end{array}$ & $\begin{array}{l}\text { High Leptin } \\
\text { and } \\
\text { Low } \\
\text { Adiponectin }\end{array}$ & $\mathbf{P}$ \\
\hline & $N=18$ & $N=18$ & \\
\hline Age (years) & $69.12 \pm 3.28$ & $70.72 \pm 5.22$ & 0.29 \\
\hline$M / F$ & $16 / 2$ & $13 / 5$ & NS \\
\hline Body weight $(\mathrm{kg})$ & $58.36 \pm 7.02$ & $80.43 \pm|3.6|$ & $<0.001$ \\
\hline BMI $\left(\mathrm{kg} / \mathrm{m}^{2}\right)$ & $23.13 \pm 2.45$ & $30.37 \pm 3.51$ & $<0.001$ \\
\hline $\begin{array}{l}\text { Waist circumference } \\
(\mathrm{cm})\end{array}$ & $78.32 \pm 7.03$ & $97.18 \pm 11.92$ & $<0.001$ \\
\hline Hip circumference $(\mathrm{cm})$ & $94.92 \pm 6.97$ & $107.00 \pm 5.30$ & $<0.001$ \\
\hline Fat body mass $(\mathrm{kg})$ & $18.43 \pm 46.47$ & $30.49 \pm 50.29$ & $<0.001$ \\
\hline Fat body mass $\%$ & $31.81 \pm 5.05$ & $38.84 \pm 4.13$ & $<0.001$ \\
\hline Lean body mass (kg) & $37.07 \pm 38.84$ & $46.05 \pm 90.53$ & $<0.001$ \\
\hline Glycemia (mg/dL) & $90.93 \pm 7.69$ & $92.89 \pm 17.97$ & 0.70 \\
\hline Tot cholesterol $(\mathrm{mg} / \mathrm{dL})$ & $225.93 \pm 28.12$ & $223.06 \pm 28.77$ & 0.77 \\
\hline HDL cholesterol (mg/dL) & $77.00 \pm 21.98$ & $54.06 \pm 11.06$ & $<0.001$ \\
\hline LDL cholesterol (mg/dl) & $133.73 \pm 25.38$ & $145.39 \pm 25.76$ & 0.20 \\
\hline Triglycerides (mg/dl) & $75.67 \pm 27.22$ & $117.17 \pm 44.58$ & 0.01 \\
\hline $\mathrm{SBP}(\mathrm{mmHg})$ & $138.88 \pm 14.52$ & $155.82 \pm 21.26$ & 0.01 \\
\hline $\mathrm{DBP}(\mathrm{mmHg})$ & $81.94 \pm 8.44$ & $85.12 \pm 9.82$ & 0.32 \\
\hline $\mathrm{PP}(\mathrm{mmHg})$ & $56.94 \pm 9.02$ & $70.71 \pm 14.10$ & 0.01 \\
\hline MBP $(\mathrm{mmHg})$ & $100.92 \pm 9.99$ & $108.69 \pm 13.07$ & 0.06 \\
\hline cf PWV (m/s) & $8.79 \pm 1.63$ & $12.04 \pm 2.39$ & $<0.001$ \\
\hline $\operatorname{cr} \mathrm{PWV}(\mathrm{m} / \mathrm{s})$ & $8.00 \pm 1.15$ & $8.22 \pm 1.43$ & 0.66 \\
\hline
\end{tabular}

Abbreviations: BMI, body mass index; SBP, systolic blood pressure; DBP, diastolic blood pressure; MBP, mean blood pressure; PP, pulse pressure; of PWV, carotid femoral pulse wave velocity; cr PWV, carotid radial pulse wave velocity; NS, not significant.

adiponectin and low leptin. Also cfPWV was significantly higher in group 2 than in group $1(1204 \pm 239 \mathrm{~m} / \mathrm{s}$ vs 879 $\pm 163 \mathrm{~m} / \mathrm{s} ; \mathrm{p}<0001)$. cr PWV was not significantly different in 2 groups of study.

In Figure 1, cfPWV values stratified for adipokine categories, after adjustment for gender, fat body mass percent, MBP, HDL cholesterol, and triglycerides are shown. After adjustment for these covariates, patients in the group with high leptin and low adiponectin (group 2) showed still higher cfPWV than patients in the group with high adiponectin and low leptin (1186 \pm $069 \mathrm{~m} / \mathrm{s}$ vs $999 \pm 069 \mathrm{~m} / \mathrm{s} ; \mathrm{p}=002$ ).

Table 3 shows a backward multiple regression model considering cfPWV as dependent variable and age, gender, MAP, HDL cholesterol, triglycerides, fat body mass percent, adipokine category as independent variables. Age, MAP, triglycerides and the category with high leptin and low adiponectin resulted to be significant predictors of cfPWV and explains $35.6 \%$ of variance.

In Table 4, a binary logistic regression model is shown that considers subclinical vascular damage (considered as cfPWV $>10 \mathrm{~m} / \mathrm{s}$ ) as a dependent variable and age, gender, MAP, fat body mass percent, triglycerides, HDL cholesterol and the category with high leptin and low adiponectin as independent variables. MAP and the category of patients with high leptin and low adiponectin resulted significant predictors of subclinical vascular damage with an OR, respectively, 1.09 (CI 103-116; p=001) and 361 (CI 119-1100; $\mathrm{p}=002$ ).

\section{Discussion}

This study shows an association between adipokines and arterial stiffness in a population of elderly patients with unknown cardiovascular disease, showing that the simultaneous presence of high leptin levels and low adiponectin levels have a synergic effect on development of subclinical vascular damage and increases the risk by 3.6 times.

In our study, there was a significant association between leptin and arterial stiffness in both genders $(\mathrm{r}=0.39$ men, $\mathrm{r}=0.36$ in women; $\mathrm{p}<0.05)$. These results confirmed previous studies in younger populations. Singhal et al showed an association between leptin and cfPWV in a group of 294 healthy adolescents who had a broad range of BMI, independently of fat body mass, blood pressure and CRP, suggesting high leptin concentration as an important mechanism for arterial stiffness and left ventricular hypertrophy observed in these patients. ${ }^{31}$

It has been shown that serum leptin levels are positively correlated with cardiovascular risk independently of fat body mass; indeed, higher serum leptin levels were shown in both women and men with myocardial infarction, independently of traditional risk factors and obesity. ${ }^{32}$

Experimental studies suggest different mechanisms by which leptin might promote arterial stiffness. Even if known central hypothalamic effects of leptin include food intake reduction and increasing energy expenditure, leptin receptors have been found in the heart, vessels, and mainly in the aorta. ${ }^{33}$ Other receptors are also present in tunica media and adventitia of arteries and inside of atherosclerotic plaques. ${ }^{34,35}$ Leptin, through these receptors, could promote vascular smooth muscle cell proliferation and migration contributing to arterial stiffness. ${ }^{18}$ Furthermore, treatment with leptin has been shown in mice to increase artery calcification. ${ }^{34}$ Moreover, previous in vitro and human studies showed that leptin also induces 


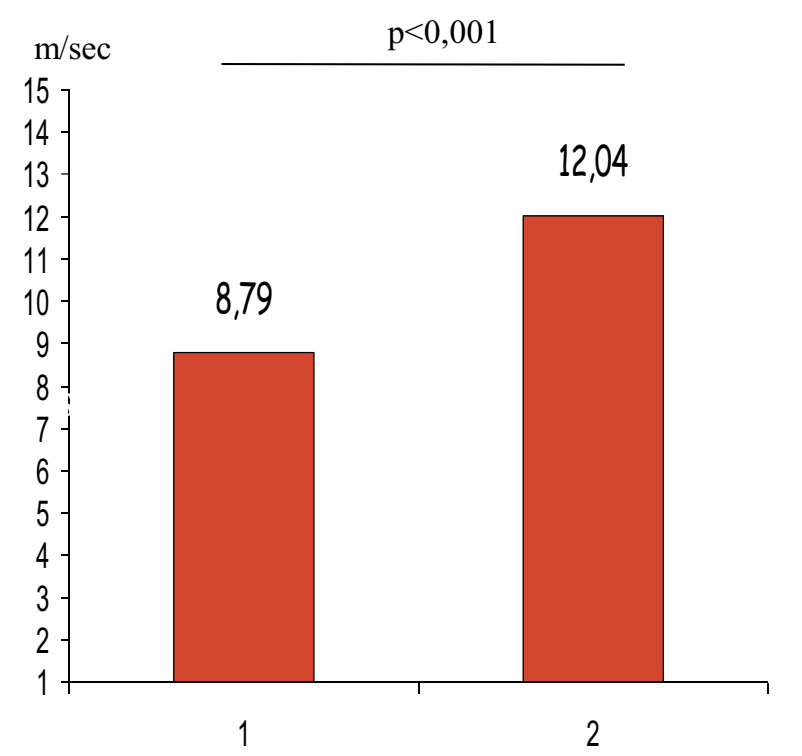

High adiponectin

\&

Low leptin

$(n=18)$
High leptin

\&

Low adiponectin

$(n=18)$

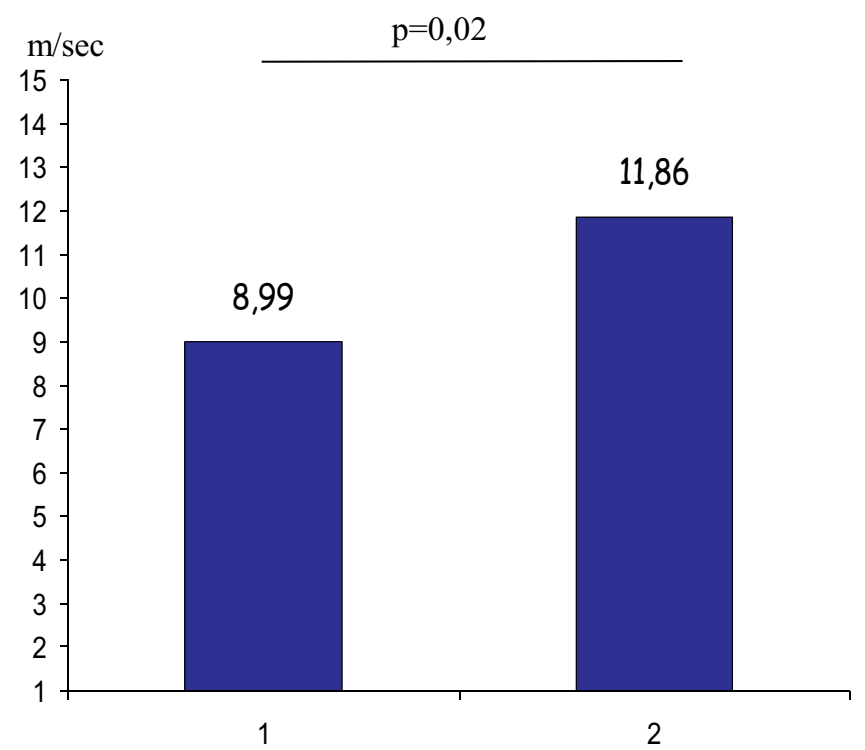

High adiponectin

\&

Low leptin

$(n=18)$

\section{High leptin \\ \& \\ Low adiponectin \\ $(n=18)$}

Figure I Carotid-femoral pulse wave velocity values in different study groups before (red columns) and after (blue columns) adjustment for gender, fat mass\%, MBP, HDL cholesterol and triglycerides.

endothelial oxidative stress and reactive oxygen species formation. ${ }^{19,35}$

The most important result of our study is the synergic effect between the presence of both low adiponectin and high leptin levels on vascular damage. When we divided the study population according to adipokine patterns, cfPWV was higher in subjects with high leptin and low adiponectin than subjects with high adiponectin and low leptin, even after adjustment for gender, fat mass percent, MAP, HDL cholesterol, and triglycerides. We adjusted the values for these variables because there was a significant difference between the 2 groups. We decided to adjust for fat mass percent instead of BMI because it is widely known that the FM \% evaluated by DXA is much

Table 3 Backward Multiple Regression Considering PWVcf as Dependent Variable and Age, Gender, MBP, HDL Cholesterol, Triglycerides, Fat Body Mass Percent, Adipokines Category as Independent Variables, in the Complete Study Population $(n=85)$

\begin{tabular}{|l|l|l|l|}
\hline Variables & Coefficient $\boldsymbol{\beta}$ & $\mathbf{P}$ & $\mathbf{R 2}$ \\
\hline Age & 0.25 & 0.02 & \\
MBP & 0.27 & 0.02 & \\
Triglycerides & 0.22 & 0.05 & \\
High leptin and low adiponectin & 0.26 & 0.02 & 0.356 \\
\hline
\end{tabular}

Abbreviations: MBP, mean blood pressure; HDL, high-density lipoprotein. more precise than BMI in predicting the quantity of adipose tissue.

Furthermore, in a model of binary logistic regression where subclinical vascular damage was considered as the dependent variable and gender, MBP, triglycerides, HDL cholesterol, low leptin/high adiponectin category as independent variables, this adverse adipokine pattern increased the risk of vascular damage (cfPWV $>10 \mathrm{~m} / \mathrm{s}$ ) by 3.61 times.

Table 4 Binary Logistic Regression Considering Subclinic Vascular Damage ( $\mathrm{Cf}$ PWF>10 m/s) as Dependent Variable and Age, Gender, MBP, Fat Body Mass Percent, Triglycerides, HDL Cholesterol and the Category with High Leptin and Low Adiponectin as Independent Variables, in the Complete Study Population $(n=85)$

\begin{tabular}{|l|l|l|l|l|l|}
\hline Variables & $\begin{array}{l}\text { Coefficient } \\
\boldsymbol{\beta}\end{array}$ & SE & OR & $\mathbf{C I}$ & $\mathbf{P}$ \\
\hline Age & 0.121 & 0.07 & 1.13 & $0.99-1.29$ & 0.07 \\
Gender & -0.20 & 1.00 & 1.14 & $0.02-1.01$ & 0.051 \\
MBP & 0.09 & 0.03 & 1.09 & $1.03-1.16$ & 0.01 \\
HDL Cholesterol & -0.02 & 0.02 & 0.98 & $0.95-1.02$ & 0.42 \\
Triglycerides & -0.06 & 0.01 & 0.99 & $0.98-1.01$ & 0.47 \\
Fat body mass \% & -0.12 & 0.07 & 0.88 & $0.77-1.02$ & 0.08 \\
High leptin and & 1.28 & 0.568 & 3.61 & $1.19-11.00$ & 0.02 \\
low adiponectin & & & & & \\
\hline
\end{tabular}

Abbreviations: MBP, mean blood pressure; HDL, High-Density Lipoprotein. 
Previously, Windham et al, in 749 individual ages 26-96 years with mean BMI $26.6 \mathrm{~kg} / \mathrm{m}^{2}$, showed that high leptin and low adiponectin were independently associated with cfPWV. ${ }^{21}$ These cytokines show a competitive effect on the vascular wall: the inflammatory activity of leptin is balanced with the anti-inflammatory activity of adiponectin. Furthermore, adiponectin seems to inhibit the remodelling of vascular extracellular matrix promoted by leptin which induces vessel fibrosis and thereby leads to arterial stiffness. ${ }^{36}$

In addition to the vascular effect, overweight and obese individuals with a higher ratio of adiponectin/leptin have a better metabolic profile. ${ }^{37}$ This protective adipokine profile is therefore related to a positive hemodynamic and metabolic pattern promoting longevity. Indeed, it was shown that centenarians have higher adiponectin levels and lower leptin levels than control individuals. ${ }^{38}$

While the majority of previous studies were conducted on patient populations with already known cardiovascular risk factors, our results were obtained from a elderly population, without diabetes and known cardiovascular diseases, and therefore without any medical therapies that could influence arterial stiffness. Actually we found some not known hypertensive subjects evaluating the study population and since hypertension is a known major determinant of arterial stiffness we adjusted the cfPWV data even for MBP comparing the group with different adipokines profile, finding significant differences between the 2 groups even after this adjustment.

In this way, a negative adipokine profile could be considered as a predisposing factor for arterial stiffness and consequently for cardiovascular disease, and this profile is recognizable at a very early stage and before the appearance of vascular damage.

We did not find a direct significant correlation between adiponectin and cfPWV, probably because of the small number of our study population. Several studies in wider populations showed a negative association between arterial stiffness and serum adiponectin concentration in healthy populations but even in hypertensive, diabetic and metabolic syndrome patients. ${ }^{20,29,39-43}$ El Khoudary et al showed that baseline adiponectin levels were independent predictors of aortic stiffness progression in a population of 240 men (40-49 years old) free of cardiovascular disease. ${ }^{27}$

In vitro studies highlighted the role of adiponectin on vascular tone regulation by increasing nitric oxide in endothelial cells. ${ }^{44}$ In addition, adiponectin may be involved in the repair of injured vessels: it was found in the subendothelial space of carotid arteries damaged by a catheter and in the endothelium of atherosclerotic vessels ${ }^{24}$ and it may prevent vascular stenosis. ${ }^{23}$

Some limitations of this study should be recognized. There was a lack of data regarding inflammation markers in order to analyse a possible link between abdominal adiposity, adipokines and vascular damage. We only evaluated 2 adipokines and probably the assessment of some others adipokines could have helped to better understand the relationships between VAT and arterial stiffness. We recruited just Caucasian elderly subjects without high comorbidity and this could be a limitation to interpret and generalize the findings. Study sample was small and for this reason we could not have found some significant differences for study variables with low effect size.

In conclusion, in this study analysing the association between adipokines and arterial stiffness in a group of elderly subjects, we found that low serum leptin level and high serum adiponectin level with triglycerides, MBP and age are predictors of arterial stiffness. Moreover, the simultaneous presence of high leptin levels and low adiponectin levels seems to have a synergic effect on development of subclinical vascular damage increasing the risk by 36 times.

\section{Disclosure}

The authors report no conflicts of interest for this work. The abstract of this paper was presented at the 9th Congress of the EUGMS (European Geriatric Medicine Society), Venice, 2-4 October 2013 as a poster presentation. The poster's abstract was published in "Poster Abstracts" in European Geriatric Medicine, Volume 4, Supplement 1, September 2013, Page S45.

\section{References}

1. Prenner SB, Chirinos JA. Arterial stiffness in diabetes mellitus. Atherosclerosis. 2015;238(2):370-379. doi:10.1016/j.atherosclerosis. 2014.12.023

2. Smulya H, Lieber A, Safar ME. Hypertension, diabetes type II and their association: role of arterial stiffness. Am J Hypertens. 2016;29:5-13. doi:10.1093/ajh/hpv107

3. Fantin F, Di Francesco V, Rossi A, et al. Abdominal obesity and subclinical vascular damage in the elderly. $J$ Hypertens. 2010;28:333-339. doi:10.1097/HJH.0b013e328333d23c

4. Fantin F, Comellato G, Rossi AP, et al. Relationship between neck circumference, insulin resistance and arterial stiffness in overweight and obese subjects. Eur J Prev Cardiol. 2017;24:1532-1540. doi: $10.1177 / 2047487317721655$

5. Strasser B, Arvandi M, Pasha EP, et al. Abdominal obesity is associated with arterial stiffness in middle-aged adults. Nutr Metab Cardiovasc Dis. 2015;25:495-502. doi:10.1016/j.numecd.2015.01. 002 
6. Fonseca-Alaniz MH, Takada J, Alonso-Vale MI, Lima FB. Adipose tissue as an endocrine organ: from theory to practice. J Pediatr (Rio J). 2007;83:S192-S203. doi:10.1590/S0021-75572007000700011

7. Kofler S, Nickel T, Weis M. Role of cytokines in cardiovascular disease: a focus on endothelial responses to inflammation. Clin Sci (Lond). 2005;108:205-2013. doi:10.1042/CS20040174

8. Fantuzzi G, Mazzone T. Adipose tissue and atherosclerosis: exploring the connection. Atheroscl Thromb Vasc Biol. 2007;27:996-1003. doi:10.1161/ATVBAHA.106.131755

9. Cnop M, Havel PJ, Utzschneider KM, et al. Relationship of adiponectin to body fat distribution, insulin sensitivity and plasma lipoproteins: evidence for independent roles of age and sex. Diabetologia. 2003;46:459-469. doi:10.1007/s00125-003-1074-z

10. Arai Y, Takayama M, Abe Y, Hirose N. Adipokines and aging. J Ateroscler Thromb. 2011;18:545-550. doi:10.5551/jat.7039

11. Zoico E, Di Francesco V, Bissoli L, Mazzali G, Fontana G. Giuliano Ket al. Interrelationship between leptin resistance, body composition and aging in elderly women. $J$ Am Geriatr Soc. 2008;56:1768-1769. doi:10.1111/j.1532-5415.2008.01811.x

12. Zamboni M, Mazzali G, Zoico E, et al. Health consequences of obesity in the elderly: a review of four unresolved questions. Int J Obes. 2005;29:1011-1029. doi:10.1038/sj.ijo.0803005

13. Scuteri A, Orru M, Morrel C, et al. Independent and addictive effects of cytokine patterns and the metabolic syndrome on arterial aging in the SardiNIA study. Atherosclerosis. 2011;215:459-464. doi:10.1016/ j.atherosclerosis.2010.12.023

14. Sabbatini AR, Fontana V, Laurent S, Moreno H. An update on the role of adipokines in arterial stiffness and hypertension. $J$ Hypertens. 2015;33:435-44. doi:10.1097/HJH.0000000000000444

15. Silva AA, Carmo J, Dubinion J, Hall JE. The role of the sympathetic nervous system in obesity-related hypertension. Curr Hypertens Rep. 2009;11:206-211. doi:10.1007/s11906-009-0036-3

16. Schillaci G, Pirro M. C-reactive protein in hypertension: clinical significance and predictive value. Nutr Metab Cardiovasc Dis. 2006;16:500-508. doi:10.1016/j.numecd.2006.05.001

17. Mahmud A, Feely J. Adiponectin and arterial stiffness. Am J Hypertens. 2005;18::1543-1548. doi:10.1016/j.amjhyper.2005.06.014

18. Oda A, Taniguchi T, Yokoyama M. Leptin stimulates rat aortic smooth muscle cell proliferation and migration. Kobe J Med Sci. 2001;47:141-150.

19. Bouloumie A, Marumo T, Lafontan M, Busse R. Leptin induces oxidative stress in human endothelial cells. FASEB J. 1999;13:1231-1238. doi:10.1096/fasebj.13.10.1231

20. Rahmouni K, Morgan DA. Hypothalamic arcuate nucleus mediates the sympathetic and arterial pressure responses to leptin. Hypertension. 2007;49::647-652. doi:10.1161/01.HYP.0000254827.59792.b2

21. Windham BG, Griswold ME, Farasat SM, et al. Influence of leptin, adiponectin, and resistin on the association between abdominal adiposity and arterial stiffness. Am J Hypertens. 2010;23:501-507. doi:10.1038/ajh.2010.8

22. Hattori Y, Suzuki M, Hattori S, Kasai K. Globular adiponectin upregulates nitric oxide production in vascular endothelial cells. Diabetologia. 2003;46:1543-1549. doi:10.1007/s00125-003-1224-3

23. Matsuda M, Shimomura I, Sata M, et al. Role of adiponectin in preventing vascular stenosis. The missing link of adipo-vascular axis. J Biol Chem. 2002;277:37487-37491.

24. Okamoto Y, Arita Y, Nishida M, et al. An adipocyte-derived plasma protein, adiponectin, adheres to injured vascular walls. Horm Metab Res. 2000;32:47-50. doi:10.1055/s-2007-978586

25. Kim DH, Kim C, Ding EL, Townsend MK, Lipsitz LA. Adiponectin levels and the risk of hypertension: a systematic review and metaanalysis. Hypertension. 2013;62:27-32. doi:10.1161/ HYPERTENSIONAHA.113.01453

26. Youn JC, Kim C, Park S, et al. Adiponectin and progression of arterial stiffness in hypertensive patients. Int J Cardiol. 2013;163:316-319. doi:10.1016/j.ijcard.2011.06.061
27. El Khoudary SR, Barinas-Mitchell E, White J, et al. Adiponectin, systolic blood pressure, and alcohol consumption are associated with more aortic stiffness progression among apparently healthy men. Atherosclerosis. 2012;225:475-480. doi:10.1016/j. atherosclerosis.2012.09.015

28. Kelly TL, Wilson KE, Heymsfield SB. Dual energy X-Ray absorptiometry body composition reference values from NHANES. PLoS One. 2009;4(9):e7038. doi:10.1371/journal.pone.0007038

29. Salvi P, Lio G, Labat C, Ricci E, Pannier B, Benetos A. Validation of a new non-invasive portable tonometer for determining arterial pressure wave and pulse wave velocity: the PulsePen device. J Hypertens. 2004;22:2285-2293. doi:10.1097/00004872-200412000-00010

30. Tanaka A, Tomiyama H, Maruhashi T, et al. Node K physiological diagnostic criteria for vascular failure. physiological diagnosis criteria for vascular failure committee. Hypertension. 2018;72 (5):1060-1071.

31. Singhal A, Farooqui IS, Cole TJ, et al. Influence of leptin on arterial distensibility: a novel link between obesity and cardiovascular disease? Circulation. 2002;106:1919-1924. doi:10.1161/01.CIR.000 0033219.24717 .52

32. Wellerstedt S, Eriksson AL, Niklason A, Ohlsson C, Hedner T. Serum leptin and myocardial infarction in hypertension. Blood Press. 2004;13:243-246. doi:10.1080/08037050410021405

33. Purdham DM, Zou MX, Rajapurohitam V, Karmazyn M. Rat heart is a site of leptin production and action. Am J Physiol Heart Circ Physiol. 2004;287:H2877-H2884. doi:10.1152/ajpheart.00499.2004

34. Parhami F, Tintut Y, Ballard FAM, Demer LL. Leptin Enhances the calcification of vascular cells: artery wall as a target of leptin. Circ Res. 2001;88::954-960. doi:10.1161/hh0901.090975

35. Yamagishi SI, Eldelstein D, Du XL, Kaneda Y, Guzman M, Brownlee M. Leptin induces mitochondrial superoxide production and monocyte chemoattractant protein-1 expression in aortic endothelial cells by increasing fatty acid oxidation via protein kinase A. $J$ Biol Chem. 2001;276:25096-25100. doi:10.1074/jbc.M007383200

36. Zhang Z, Wang F, Wang BJ, et al. Inhibition of leptin-induced vascular extracellular matrix remodelling by adiponectin. $J \mathrm{Mol}$ Endocrinol. 2014;53(2):145-154. doi:10.1530/JME-14-0027

37. Vega GL, Grundy SM. Metabolic risk susceptibility in men is partially related to adiponectin/leptin ratio. J Obes. 2013;2013:409679. doi:10.1155/2013/409679

38. Arai Y, Takayama M, Abe Y, Hirose N. Adipokines and aging. J Atheroscler Thromb. 2011;18:545-50.

39. Snijder MB, Flyvbjerg A, Stehouwer CD, et al. Relationship of adiposity with arterial stiffness as mediated by adiponectin in older men and women: the Hoorn Study. Eur $J$ Endocrinol. 2009;160:387-395. doi:10.1530/EJE-08-0817

40. Aso Y, Wakabayashi S, Terasawa T, et al. Elevation of serum high molecular weight adiponectin in patients with Type 2 diabetes and orthostatic hypotension: association with arterial stiffness and hypercoagulability. Diabet Med. 2012;29:80-87. doi:10.1111/j.14645491.2011.03364.x

41. Tsioufis C, Kyvelou S, Dimitriadis K, et al. The diverse associations of uric acid with low-grade inflammation, adiponectin and arterial stiffness in never-treated hypertensives. J Hum Hypertens. 2011;25:554-559. doi:10.1038/jhh.2010.98

42. Kim OY, Lim HH, Lee MJ, Kim JY, Lee JH. Association of fatty acid composition in serum phospholipids with metabolic syndrome and arterial stiffness. Nutr Metab Cardiovasc Dis. 2013;23:366-374. doi:10.1016/j.numecd.2011.06.006

43. Sung SH, Chuang SY, Sheu WH, Lee WJ, Chou P, Chen CH. Relation of adiponectin and high-sensitivity C-reactive protein to pulse-wave velocity and $\mathrm{N}$-terminal pro-B-type natriuretic peptide in the general population. Am J Cardiol. 2009;103::1411-1416. doi:10.1016/j.amjcard.2009.01.355

44. Chen H, Montagnani M, Funahashi T, Shimomura I, Quon MJ. Adiponectin simulates production of nitric oxide in vascular endothelial cells. J Biol Chem. 2003;46:1543-1549. 


\section{Publish your work in this journal}

Vascular Health and Risk Management is an international, peerreviewed journal of therapeutics and risk management, focusing on concise rapid reporting of clinical studies on the processes involved in the maintenance of vascular health; the monitoring, prevention and treatment of vascular disease and its sequelae; and the involvement of metabolic disorders, particularly diabetes. This journal is indexed on PubMed Central and MedLine. The manuscript management system is completely online and includes a very quick and fair peerreview system, which is all easy to use. Visit http://www.dovepress. com/testimonials.php to read real quotes from published authors.

Submit your manuscript here: https://www.dovepress.com/vascular-health-and-risk-management-journal 